\title{
CORONAVIRUS
}

Cite as: A. Bharat et al., Sci. Transl. Med.

10.1126/scitranslmed.abe4282 (2020).

\section{Lung transplantation for patients with severe COVID-19}

\author{
Ankit Bharat ${ }^{*}$, Melissa Querrey ${ }^{1}$, Nikolay S. Markov², Samuel Kim¹, Chitaru Kurihara ${ }^{1}$, Rafael Garza-Castillon', \\ Adwaiy Manerikar', Ali Shilatifard ${ }^{3}$, Rade Tomic ${ }^{2}$, Yuliya Politanska ${ }^{2}$, Hiam Abdala-Valencia ${ }^{2}$, Anjana V. \\ Yeldandi ${ }^{4}$, Jon W. Lomasney ${ }^{4}$, Alexander V. Misharin² ${ }^{2}$ G.R. Scott Budinger ${ }^{2}$ \\ 1Division of Thoracic Surgery, Northwestern Memorial Hospital, Feinberg School of Medicine, Northwestern University, Chicago, Illinois 60611, USA. 2Division of Pulmonary \\ and Critical Care Medicine, Northwestern Memorial Hospital, Feinberg School of Medicine, Northwestern University, Chicago, Illinois 60611, USA. ${ }^{3}$ Department of \\ Biochemistry and Molecular Genetics, Northwestern Memorial Hospital, Feinberg School of Medicine, Northwestern University, Chicago, Illinois 60611, USA. ${ }^{4}$ Department of \\ Pathology, Northwestern Memorial Hospital, Feinberg School of Medicine, Northwestern University, Chicago, Illinois 60611, USA. \\ *Corresponding author. Email: abharat@nm.org
}

Lung transplantation can potentially be a life-saving treatment for patients with non-resolving COVID-19associated respiratory failure. Concerns limiting lung transplantation include recurrence of SARS-CoV-2 infection in the allograft, technical challenges imposed by viral-mediated injury to the native lung, and the potential risk for allograft infection by pathogens causing ventilator-associated pneumonia in the native lung. Importantly, the native lung might recover, resulting in long-term outcomes preferable to those of transplant. Here, we report the results of lung transplantation in three patients with non-resolving COVID19-associated respiratory failure. We performed single molecule fluorescent in situ hybridization (smFISH) to detect both positive and negative strands of SARS-CoV-2 RNA in explanted lung tissue from the three patients and in additional control lung tissue samples. We conducted extracellular matrix imaging and single cell RNA sequencing on explanted lung tissue from the three patients who underwent transplantation and on warm post-mortem lung biopsies from two patients who had died from COVID-19-associated pneumonia. Lungs from these five patients with prolonged COVID-19 disease were free of SARS-CoV-2 as detected by smFISH, but pathology showed extensive evidence of injury and fibrosis that resembled endstage pulmonary fibrosis. Using machine learning, we compared single cell RNA sequencing data from the lungs of patients with late stage COVID-19 to that from the lungs of patients with pulmonary fibrosis and identified similarities in gene expression across cell lineages. Our findings suggest that some patients with severe COVID-19 develop fibrotic lung disease for which lung transplantation is their only option for survival.

\section{INTRODUCTION}

As of November $20^{\text {th }} 2020$, over 12 million people have been diagnosed with coronavirus disease (COVID-19) in the United States and nearly 260,000 have died (https://coronavirus.jhu.edu), with greater than 4.6 million active cases. Globally, 57.9 million cases have been reported with about 1.4 million deaths. Additionally, there are greater than 16 million active cases worldwide of which 102,303 remain in serious or critical condition (https://www.worldometers.info). In many patients SARSCoV-2 infection can progress to severe respiratory failure and Acute Respiratory Distress Syndrome (ARDS) requiring mechanical ventilation $(1,2)$. The reported mortality of patients with COVID-19 requiring mechanical ventilation is between $20-40 \%$, despite optimized supportive care $(3,4)$.

Lung transplantation is a life-saving treatment for a variety of end-stage lung diseases (5). Annually, more than 2,700 lung transplants are performed in the United States with a 1year survival of over $90 \%$ and a 3 -year survival of over $75 \%$ (www.srtr.org). Several concerns limit the use of lung transplantation as a therapy for patients with severe ARDS secondary to COVID-19. First, there is a concern that SARS-CoV2 or superinfecting pathogens associated with viral pneumonia in the native lung might recur in the allograft. Second, severe vascular and pleural damage secondary to SARS-CoV2 infection might create technical barriers to transplant, increase the time that tissues are ischemic, and worsen outcomes. Third, the severe deconditioning associated with prolonged mechanical ventilation, sedation and neuromuscular blockade might complicate recovery after transplant. Fourth, and perhaps most importantly, there is uncertainty as to whether the lung can repair itself after severe SARSCoV-2-associated pneumonia; effective lung repair would result in long-term outcomes better than lung transplantation.

Here, we successfully performed lung transplantation in three patients with SARS-CoV-2 infection-associated pneumonia, who required prolonged mechanical ventilation and extracorporeal membrane oxygenation (ECMO) support and 
in whom recovery was determined to be unlikely. We examined explanted native lung tissue from the three transplant recipients as well as postmortem lung tissue from patients with COVID-19 who had died of ARDS. Histopathology, single molecule fluorescent in situ hybridization (sm-FISH) for detecting SARS-CoV-2 RNA, tissue clearing to image extracellular matrix organization, and single cell RNA sequencing were conducted on the lung tissue samples. Lung histology and extracellular matrix imaging revealed evidence of severe fibrosis in the explanted lungs. SARS-CoV-2 viral transcripts were not detected in the lung explants using sm-FISH and there was no evidence of recurrent SARS-CoV-2 infection in the allograft. Machine learning-based analysis of single cell RNA sequencing data revealed similarities between lung tissue from patients with COVID-19-induced respiratory failure and published RNA sequencing data sets derived from lung tissue from patients with pulmonary fibrosis, suggestive of common pathways leading to irreversible lung tissue damage and fibrosis. We found that lung disease after severe and prolonged SARS-CoV-2 infection-associated ARDS shared pathological and molecular features with pulmonary fibrosis requiring lung transplantation, suggesting that lung transplantation may be the only option for survival in these patients.

\section{RESULTS}

\section{Clinical profiles of study participants}

The clinical profiles of three patients with COVID-19 (cases 1,2, and 3), who underwent bilateral lung transplantation, are presented below and in Table 1 . In addition to these three cases, lung tissue samples from other patients with lung disease were also analyzed (Table S1). These included postmortem lung biopsies from two patients who had died from severe COVID-19 after prolonged mechanical ventilation and ECMO support (referred to as PMB1 and PMB2); a biopsy from a donor lung from an unrelated transplant (referred to as donor 1); a biopsy of the donor lung from the first lung transplant (referred to as donor 2); native lungs explanted from two patients who underwent lung transplantation for idiopathic pulmonary fibrosis (referred to as IPF1 and IPF2); a control autopsy lung specimen from a patient who died from pulmonary embolism without marked lung pathology (referred to as PE control); and a lung biopsy sample from a patient who died from SARS-CoV-2-associated pneumonia while receiving palliative care (referred to as Palliative COVID-19).

\section{Clinical Profile of Case 1}

A 28-year-old Latina female with neuromyelitis optica, who was being treated with rituxamab and mycophenolate mofetil, presented with two weeks of poor appetite, gastrointestinal discomfort, fevers, cough, dyspnea on exertion, and pleuritic chest pain and was diagnosed with COVID-19. Upon presentation, she exhibited severe hypoxemia that was refractory to oxygen therapy, and underwent emergency intubation. Nasopharyngeal swab and bronchoalveolar lavage were positive by PCR for SARS-CoV-2 RNA. She received mechanical ventilation according to ARDSNET guidelines (6) using a higher positive end-expiratory pressure (PEEP)/lower fraction of inspired oxygen (FiO2) strategy. Her partial pressure of oxygen $(\mathrm{PaO} 2) / \mathrm{FiO} 2$ ratio was $<150$ persistently and she was ventilated prone for a total of three 16 hour periods in the first week of her illness (7). Bronchoscopic sampling of the alveolar space was performed after intubation and when clinical co-infection or super-infection with respiratory pathogens was suspected. The results of quantitative cultures and multiplex PCR detection for respiratory pathogens (BioFire FilmArray Respiratory 2 Panel) was used to manage antibiotic treatment over the course of her hospitalization. Despite these interventions, the patient's blood oxygenation concentrations continued to decrease and she was placed on venovenous extracorporeal membrane oxygenation (ECMO). Her clinical course was complicated by a right-sided pneumothorax requiring multiple pleural tubes and the development of pneumonia caused by Serratia marcescens with left lower lung necrosis (Fig. 1A, B). Later in her disease course she developed elevated pulmonary arterial pressure $(71 / 49 \mathrm{mmHg})$, and echocardiography showed moderate right ventricular dysfunction with severe tricuspid regurgitation and congestive hepatopathy. Systemic anticoagulation was initiated but was complicated by a hemothorax and a liver capsular bleed necessitating emergent exploratory laparotomy. Throughout her medical course, she received broad-spectrum and pathogen-directed antibiotics, remdesivir, hydroxychloroquine, tocilizumab, and convalescent plasma. Her lung compliance, gas exchange, chest radiographs, and chest tomogram showed worsening or no improvement over the course of her stay in the intensive care unit (ICU). Beginning 6 weeks from the onset of mechanical ventilation, PCR testing for SARSCoV-2 in bronchoalveolar lavage fluid samples was repeatedly negative. Weaning the patient off of the ECMO was attempted over the course of several weeks with no success and she was listed for lung transplantation. Prior to lung transplantation, several attempts were made to wean the patient off of sedation but they were associated with severe hypoxemia and hemodynamic collapse. Computed tomography imaging of the head and electroencephalograms did not demonstrate irreversible brain injury but were suggestive of delirium. After obtaining consent by the designated medical power of attorney, the patient was listed for lung transplantation. Two days after listing, she received a bilateral lung transplant using central veno-arterial ECMO. Severe dense vascular adhesions were noted in both of the patient's native lungs with severe distortion of hilar planes and reactive lymphadenopathy (Fig. 1C). Following lung transplantation, she received maintenance immunosuppression with tacrolimus, 
mycophenolate mofetil, and prednisone. Post-transplant, her sedation was stopped and she awakened without respiratory distress or hemodynamic instability. In the ensuing two weeks, she was separated from the veno-venous-ECMO as well as from mechanical ventilation and was discharged for inpatient rehabilitation 4 weeks after transplantation. Her neurocognitive status and muscular strength improved rapidly following lung transplantation. About five months after transplantation, the patient demonstrated oxygen saturations above $98 \%$ when breathing room air and reported independence in activities of daily living.

\section{Clinical Profile of Case 2.}

A 62-year-old male with hypertension was placed on venovenous-ECMO for severe COVID-19-induced ARDS before transfer to our institution. During his clinical course, he received remdesivir, convalescent plasma, antibiotics, and dexamethasone. His pre-transplant hospital stay was complicated by recurrent pneumonia caused by Pseudomona aeruginosa, hemothorax and empyema requiring thoracotomy and lung decortication (Fig. 1D, E, F). Lung compliance and blood oxygenation failed to recover and he could not be weaned from the veno-venous-ECMO. Beginning 4 weeks after hospitalization, repeated bronchoscopic sampling of bronchoalveolar fluid was negative for SARS-CoV-2 RNA by PCR. Prior to transplant, the patient was awake and participated in physical rehabilitation in the ICU. After 100 days on veno-venous-ECMO support, there were no signs of lung recovery; he was listed for transplant and underwent bilateral lung transplantation three days later. The intraoperative findings were similar to the first patient, but increased complexity was encountered due to liquefactive necrosis from secondary Pseudomonas pneumonia and the prior lung decortication procedure. There was complete loss of normal mediastinal tissue planes and extensive pleuritis in the explanted native lungs (Fig. $1 \mathrm{~F}$ ), similar to the explanted lungs of the first patient (Fig. 1G). Four months following lung transplantation, the patient had oxygen saturations over $97 \%$ when breathing room air and reported independence in activities of daily living.

\section{Clinical Profile of Case 3.}

A 43-year-old man with medically controlled type 2 diabetes mellitus required mechanical ventilation and veno-venous-ECMO three and six days, respectively, after presenting with acute hypoxemic respiratory failure to an outside institution. His medical course was complicated by an asystolic cardiac arrest on day 23, heparin-induced thrombocytopenia, a left frontal lobe infarct of the cerebral cortex, Serratia marcescens-mediated pneumonia and bacteremia, acute kidney injury, a left hemothorax requiring thoracotomy and lung decortication, a right pneumothorax requiring tube thoracostomy, hypernatremia associated with seizures, malnutrition, and a tracheostomy. Despite these complications, he was weaned off sedation and was able to participate in physical rehabilitation in the ICU before being considered for lung transplantation. During his clinical course, he received remdesivir, convalescent plasma, pathogen-directed antibiotics, as well as steroids. From four weeks after intubation, repeated bronchoscopic sampling of bronchoalveolar fluid was negative for SARS-CoV-2 RNA by PCR. However, due to the failure of lung recovery with increasing clinical signs of progressive lung fibrosis, he was transferred to our center. He was evaluated for lung transplant and listed. Six days later, he underwent bilateral lung transplantation using central veno-arterial-ECMO, approximately 90 days after the initial development of ARDS (Fig. 1H, I). Given his recent medical history of heparin allergy and heparin-induced thrombocytopenia, we performed the lung transplantation without the use of anticoagulation (8-11). The patient was found to have severe pulmonary hypertension with moderate right ventricular dysfunction. Increased surgical complexity including severe pleural and mediastinal adhesions with lymphadenopathy obscuring the mediastinal structures in the native lungs was encountered, likely secondary to the prior thoracotomy and hemothorax and ventilator-associated pneumonia (Fig. 1J). About three months following lung transplantation, the patient had oxygen saturations over $95 \%$ when breathing room air and continued to improve regarding neurocognitive status and muscular strength at an inpatient rehabilitation facility.

\section{Histological Evaluation of Lung Tissue Biopsies.}

At the time of transplantation, the lungs from the three patients were edematous and heavy (right lung weight 595.7 $\mathrm{g}$ case $1,476.3 \mathrm{~g}$ case $2,345 \mathrm{~g}$ case 3 ; left lung weight $496.2 \mathrm{~g}$ case $1,548.2 \mathrm{~g}$ case $2,353.9 \mathrm{~g}$ case 3 ). In case 1 , the external surface of the lung explant had a nodular appearance and dense fibrous adhesions between the lobes (Fig. 2A). In all three patients, there were dense pleural adhesions, and the first patient had visible pleural blebs and cysts (Fig. 2A-C). In the three lung explants examined, cavities with necrosis were observed. Post-operative cultures confirmed the presence of bacterial pathogens in these cavities, which were detected preoperatively by PCR in BAL fluid.

Lung tissue obtained from cases 1,2 , and 3 at the time of transplantation and from warm autopsy material obtained within 1 hour of death had several shared features (Fig. 2 and Figure S1) that were consistent with other autopsy series from patients who had died from COVID-19 (12). These features included regions of diffuse alveolar hemorrhage, as well as acute bronchopneumonia from secondary bacterial infection (Fig. 2D,E,F). In other areas, the lungs showed various stages of a pattern consistent with an acute interstitial pneumonitis including acute neutrophilic infiltrates within the interstitium and alveolar spaces, interstitial expansion by fibrosis, bronchiolization of alveoli and areas of microscopic 
honeycomb changes (Fig. 2G, H). Additionally, organizing pneumonia showing whorls of fibroblasts in the airways and interstitial expansion was observed (Fig. 2I). Rare microthrombi were observed, some with recanalization (Fig. 2J). Case 2 developed lung infarction and necrosis secondary to larger thrombi. Alveolar macrophages within the airspaces stained positive for iron, confirming the presence of alveolar hemorrhage (Fig. 2K, L). Sections from the lung explant of case 1 showed multiple cystic structures in various stages of formation. Early cyst formation consisted of acute bronchilolitis with intraluminal neutrophils (Fig. 2M), then chronic inflammation with histiocytic cells and giant cells lining the bronchioles (Fig. 2N, S1I). More mature cysts were devoid of inflammatory cells and some were associated with fibrosis (Fig. 2O, P, Q, R). Whereas the changes in cyst formation we observed might reflect changes associated with prolonged mechanical ventilation, similar structures were observed in another patient who died from COVID-19 after deciding to forgo mechanical ventilation. Some of these cystic changes with histiocytic and giant cell responses were reminiscent of pneumatoceles possibly from peripheral airway destruction as a result of viral or bacterial infection.

\section{Analysis of explanted and warm autopsy lung tissue.}

We examined the explanted lung tissue of the three lung transplant patients (cases 1, 2, and 3) obtained 40 and 100 days after the initiation of mechanical ventilation. Prior to transplant, BAL fluid samples were tested repeatedly for the presence of SARS-CoV-2 by PCR testing and were found to be negative. SARS-CoV-2 is a positive RNA strand virus and during replication a negative strand is transiently formed to serve as a template for the positive strand (13). The presence of both positive and negative RNA strands in a cell is suggestive of ongoing viral replication. Accordingly, we performed sm-FISH using the RNAscope assay with probes designed to detect positive and negative RNA strands of SARS-CoV-2 in sections of explanted lung tissue. Lung tissue obtained from a patient who had forgone therapy for respiratory failure secondary to COVID-19 (Palliative COVID-19, control) showed many positive and few negative strands of SARS-CoV-2 RNA (Fig. 3A-D). In contrast, we were unable to detect virus using this technology in the lung explants from cases 1 and 2 who underwent lung transplantation (Fig. 3E-H) or in post-mortem lung tissue from COVID-19 patients who had undergone prolonged extracorporeal life support (Fig. 3I, PMB1, Table S1). Post-operative PCR performed on BAL fluid samples confirmed a lack of SARS-CoV-2 recurrence after lung transplantation.

Pulmonary fibrosis is characterized by the development of aberrant and disorganized collagen deposition in the alveolar regions of the lung. We sought to compare the three-dimensional matrix organization of end-stage lung tissue from patients with SARS-CoV-2-associated pneumonia and patients undergoing lung transplantation for idiopathic pulmonary fibrosis. We adapted our protocols for tissue clearing using a method called SHIELD (stabilization under harsh conditions via intramolecular epoxide linkages to prevent degradation) to generate and image the 3D matrix organization of lung tissue. A postmortem lung sample from a patient who had died from pulmonary embolism with relatively normal histology (PE Control, Fig. 3J, Movie S1) showed bands of matrix surrounding terminal airways with wispy lines defining the airways and airspaces that were devoid of cells or matrix. Images from explanted lung tissue from case 1 showed a complete absence of matrix organization with punctate islands of cells surrounding fibrotic airway regions (Fig. 3K). A similar pattern was observed in lung tissue from two patients who had died from severe COVID-19-associated pneumonia after a similar duration of mechanical ventilation (patients PBM1 and PBM2; Fig. 3L-M; Movie S1). This disorganized matrix pattern was also observed in lung explant sections from two patients with idiopathic pulmonary fibrosis who underwent lung transplantation (patients IPF1 and IPF2, Fig. 3N-O, Movie S1).

\section{Transcriptional analysis of lung explant and warm au- topsy samples}

Our histological and extracellular matrix analysis demonstrated many similarities between the lung tissue from patients with end-stage COVID-19 and patients with end-stage pulmonary fibrosis. To test whether COVID-19-associated fibrosis correlated with specific immune, epithelial and mesenchymal cell populations known to be associated with development of pulmonary fibrosis (14-17), we performed single-cell RNA sequencing on lung explant tissue from the first lung transplant patient (case 1), postmortem lung samples from patients PMB1 and PMB2 and two normal donor lung samples (donor 1, donor 2). Consistent with our smFISH results, we did not detect SARS-CoV-2 RNA transcripts in lung tissue samples from PMB1 and PMB2 patients with end-stage COVID-19 disease. We compared our single-cell RNA sequencing data to that for lung tissue from patients with pulmonary fibrosis using a well-annotated atlas generated by Habermann et al. (16) and a transfer learning approach called scArches (22). From our single-cell RNA sequencing data, we identified cell populations (epithelial cells, macrophages and mesenchymal cells) in postmortem lung tissue from patients PBM1 and PBM2 that were very similar to those reported in lung tissue from patients with pulmonary fibrosis (Fig. 4A, C, E; Fig. S2A,B). In contrast, our single-cell RNA sequencing data for normal donor lung tissue identified cell populations that mapped onto corresponding cell populations in normal lungs in the reference dataset (Fig. 4A, C, E) (16).

The alignment of cell populations in lung tissue from patients with end-stage COVID-19 and patients with end-stage 
pulmonary fibrosis prompted us to explore similarities and differences in these cell populations between these two disease groups. We began with epithelial cells, as an emerging literature suggests that pulmonary fibrosis begins with disordered alveolar epithelial repair. Specifically, as alveolar type 2 cells differentiate into alveolar type 1 cells, a transitional cell population of cells characterized by increased expression of $K r t 8$ arises in animal models of pulmonary fibrosis (18-21). An analogous population of cells characterized by the expression of TP63, KRT5, KRT17, LAMB3, LAMC2, VIM, CHD2, FN1, COLIA1, TNC, HMGA2 and several senescence markers (CDKN1A, CDKN2A, CCND1, CCND2, MDM2, SERPINE1) accumulates during pulmonary fibrosis in humans. These cells have been suggested to contribute to disease pathogenesis through expression of TGFB1, ITGAV and ITGB6 (the KRT5$K R T 17+$ epithelial cell cluster in the Habermann et al. dataset) $(16,17)$. A similar epithelial cell population with similar gene expression patterns was observed in lung tissue from case 1 and from patients PMB1 and PMB2; this cell population was absent from donor lung tissue (donor 1, donor 2) (Fig. 4A, B, Figure S2C, Table S3). We validated the presence of this epithelial cell population in the lung explant parenchyma of two COVID-19 patients (cases 1 and 2), who underwent lung transplantation (Fig. 4G-I). Warm autopsy lung tissue from a COVID-19 patient with early disease, who did not receive mechanical ventilation and had lung parenchyma free of fibrotic changes, was used as a control (Palliative COVID-19; Fig. 4G). In normal healthy lung, expression of KRT17 is restricted to basal, club, ciliated and alveolar type 1 cells $(14,16)$. We observed flat KRT17-positive cells resembling alveolar type 1 cells in the distal lung of the patient with early COVID-19 disease who died (Palliative COVID-19, Fig. $4 \mathrm{G})$. In contrast, explanted lung tissue from cases 1 and 2 who underwent lung transplantation contained KRT17-positive cells that were localized near COL1A1-positive cells and in some regions appeared to line the cyst-like structures revealed by standard histology (Fig. 4H, I). Direct comparison of differential gene expression in basal cells (cluster 1) or KRT17+KRT5 - cells (cluster 7) in lung tissue from COVID-19 patients or patients with pulmonary fibrosis did not identify genes uniquely present in one condition, highlighting similarities between these two diseases (Table S4).

Lung epithelial injury results in the continuous recruitment of monocyte-derived alveolar macrophages to the alveolar space that is required for the development of fibrosis in animal models (22). Indeed, we observed abundant macrophages in the airways and alveolar spaces of lung explants from cases 1 and 2 (Figs. 2, S1). Human profibrotic monocytederived alveolar macrophages are characterized by expression of SPP1, ILRN, MMP9, CHI3L1, and PLA2G7 and reduced expression of FABP4, INHBA and PPARG, which mark tissueresident homeostatic alveolar macrophages present in the normal lung (14, 16, 17, 23). Tissue-resident alveolar macrophages were present in healthy donor lungs and in a reference dataset (clusters 5,6 ), but were nearly absent in lung samples from patients with COVID-19 (Fig. 4C, D, Figure S2D, Table S4. In contrast, macrophages with a transcriptional profile matching profibrotic monocyte-derived alveolar macrophages (cluster 4) were observed in all three patients with end-stage COVID-19 showing pulmonary fibrosis and in patients with other fibrotic lung diseases; these cells were not observed in healthy donor lungs (Figure S2D). Direct comparison of differential gene expression in cluster 4 macrophages between patients with pulmonary fibrosis and patients with COVID-19 demonstrated similarities between these two diseases (Table S4). Our analysis also identified a small group of cells in the lung samples from patient PMB1 and case 1 that expressed genes including AK5, SIGLEC15, CKB and SLC9B2, suggesting that these cells could have been osteoclasts in areas of lung necrosis and calcification (Fig. 4D, Figure S2F). Another population of macrophages (cluster 3) was enriched in the lung explant from case 1, but not in postmortem biopsies from patients PMB1 and PMB2. These macrophages expressed genes involved in iron (SLC4OA1, CD163) and lipid (MERTK, PLTP, ABCA1) metabolism, and cell motility and immune signaling (MARCKS, TLR2, CCL2O), potentially reflecting ongoing inflammation (Fig. 4C, D, Figure S2D).

Profibrotic macrophages are thought to activate and stimulate the proliferation of fibroblasts by forming self-sustaining cellular circuits maintained by growth factor release from fibroblasts and macrophages $(24,25)$. The scArches projection identified several clusters of mesenchymal cells including subsets of fibroblasts, myofibroblasts, smooth muscle cells and mesothelial cells in normal donor lung tissue and lung tissue from end-stage COVID-19 patients (Fig. 4E, F; Table S3). Fibroblast clusters 1 and 2 (which matched myofibroblasts in the reference dataset) were overrepresented in lung samples from patients with COVID-19 (Figure S3E). Cluster 2 cells showed increased expression of POSTN and COLIA1 and other extracellular matrix genes implicated in pulmonary fibrosis (Fig. 4F, Table S3). Gene expression profiles for fibroblasts in lung tissue from patients with pulmonary fibrosis and patients with severe COVID-19 were similar (Table S5)

\section{DISCUSSION}

We performed successful lung transplantation in three patients with respiratory failure that was secondary to SARS$\mathrm{CoV}$-2-induced pneumonia. All patients had severe disease and required ECMO to maintain adequate oxygenation. Furthermore, these three patients had similar complications from SARS-CoV-2 infection, which necessitated prolonged supportive ICU care. Complications included markedly reduced lung compliance, repeated episodes of ventilator-associated pneumonia with increasingly resistant nosocomial pathogens, pneumothoraces requiring repeated tube 
thoracostomy, and bleeding into both the pleural space and airways. In addition, the pathology of lung explants from these patients showed extensive and severe damage with marked similarities. These included diffuse alveolar damage, areas of bronchopneumonia with necrosis, extensive pleural inflammation, rare microthrombi, alveolar hemorrhage, and the accumulation of hemosiderin-labeled alveolar macrophages and occasional giant cells in the lung. In addition, the explanted lungs of the first two patients (cases 1 and 2) showed extensive bilateral cysts that were visible on lung sections by microscopy. Microscopic examination revealed that these cysts were extensive, variable in size and were lined by dysplastic cuboidal or sometimes squamous epithelium. In the interstitium surrounding these cysts, the normal alveolar architecture was largely lost with extensive interstitial thickening and fibrosis. Histological features of both acute and end-stage lung fibrosis in patients with severe COVID-19 may be the result of ongoing acute lung injury from SARS-CoV-2induced pneumonia combined with complicating factors including nosocomial pneumonias, ventilator-induced lung injury and thrombosis. Nevertheless, our pathological findings suggested that the damage and destruction to the lungs were irreversible, and lung transplantation was the only viable treatment option for these three patients.

Given that the duration of SARS-CoV-2 infection in the lungs of patients with severe disease is uncertain, we were concerned about ongoing SARS-CoV-2 infection at the time of lung transplantation and potential re-infection of the allograft, particularly in our first patient (case 1) who had received immunosuppression with rituximab and mycophenolate prior to her diagnosis with COVID-19. Accordingly, we performed repeated bronchoscopic sampling of multiple lung regions prior to transplant and tested samples by PCR. Reassuringly, we did not detect viral transcripts either by single-cell RNA sequencing or by sm-FISH, suggesting that bronchoscopic sampling is a clinically useful method to exclude SARS-CoV-2 infection prior to consideration for lung transplant. Our data are consistent with recent studies suggesting that it is rare to detect replicating virus more than 10 days after infection with SARS-CoV-2 (26-28).

We treated the three patients who underwent lung transplantation for COVID-19 with a typical three-drug immunosuppression regimen including calcineurin inhibitors, an anti-metabolite, and steroids. They were also administered solumedrol as well as basiliximab prior to reperfusion as part of our induction immunosuppression protocol for all lung transplant patients. In addition, they received antimicrobial drugs directed toward the pathogens isolated from the native lungs prior to transplantation. All patients underwent repeat bronchoscopy following lung transplantation to rule out recurrence of infection with SARS-CoV-2 and bacterial pathogens. The consideration of lung transplantation for these three patients required certain deviations from the standard process. First, we did not have the opportunity to discuss the option of lung transplantation with the first patient given the inability to wean her off sedation. Hence, we relied on the medical power of attorney for decision making. Second, these patients developed multiple nosocomial complications, neuromuscular deconditioning, and malnutrition, due to their complicated medical course, which may be an impediment to transplantation in patients with long-standing end-stage lung disease. Whereas these factors are relative contraindications for lung transplantation, we reasoned that the normal functional status of the patients prior to their SARS-CoV-2induced pneumonia would reduce the impact of these factors on recovery following lung transplantation. This is partly supported at least anecdotally by their outcomes to date. Importantly, these three patients had single irreversible organ (lung) failure at the time of lung transplantation, which increased the likelihood of favorable post-transplant outcomes. Finally, given the low likelihood of malignancy in these patients based on medical history, we omitted certain investigations directed toward cancer screening such as colonoscopy and mammography in these patients. Whereas longer-term followup in larger cohorts is needed, our experience supports the safety and feasibility of lung transplantation in carefully selected patients as a life-saving treatment despite a complex pre-transplant medical course.

An emerging literature suggests a model for pulmonary fibrosis in which injury, often virally mediated, to the alveolar epithelium triggers the recruitment of monocyte-derived alveolar macrophages to the alveolar space (29). These macrophages function to seal the wound, in the process forming reciprocal circuits with fibroblasts in which macrophages produce factors stimulating fibroblast proliferation and matrix production, such as PDGFA or sphingosine 1-phospate, while fibroblasts produce M-CSF that maintains monocytederived alveolar macrophages in the lung alveolar niche (25). Meanwhile, alveolar type 2 cells and local alveolar epithelial progenitor cells differentiate into type 1 cells in response to incompletely understood signals $(20,30-32)$. Failed injury repair allows macrophage-fibroblast circuits to persist, eventually filling the interstitium with matrix proteins and fibroblasts. With single cell RNA sequencing, we observed similarities between the end stages of pulmonary fibrosis and COVID-19-mediated pneumonia. Specifically, we observed the emergence of an abnormal population of basaloid-like epithelial cells expressing Keratin-17 that have been observed lining fibroblastic foci in patients with idiopathic pulmonary fibrosis (IPF), as well as profibrotic macrophages and myofibroblasts $(14,16,17)$. Furthermore, both patients with IPF and those with end-stage COVID-19 pneumonia showed an increase in disorganized matrix deposition in the lungs. However, it is likely that the pathogenesis of pulmonary fibrosis 
in these patients is multifactorial with contributions from the cytopathic effects of the virus, inflammation, trauma related to the ventilator (barotrauma), and secondary bacterial pneumonia. Nevertheless, collectively our data suggest that some patients with severe COVID-19 develop an irreversible fibrotic lung disease for which transplantation is likely their only option for survival (33).

We offer some recommendations based on our experience. First, we propose bilateral rather than single lung transplantation for patients with severe COVID-19 as all of our native lung explant samples included cavitary areas of bronchopneumonia and all of our recipients developed secondary pulmonary hypertension. Second, lung transplant should only be considered when sufficient time has elapsed since the onset of ARDS and lung recovery is deemed unlikely, that is typically after 4-6 weeks of mechanical ventilation, in the absence of severe complications necessitating earlier transplant. If validated, the identification of KRT17+KRT5basaloid cells or profibrotic alveolar macrophages in bronchoscopic biopsies may assist in identifying patients with irreversible lung fibrosis in the future. Third, the patients should be involved in the transplant decision whenever possible, recognizing that in a small group of patients who require sedation for hemodynamic and respiratory stability, the consent to proceed with transplantation can be made through a reliable medical power of attorney, aligned with the patient's health goals. Fourth, we required two negative PCR tests of bronchoalveolar fluid or nasopharyngeal swabs in non-intubated patients, prior to their listing for lung transplant to ensure clearance of the virus (26-28). Fifth, we recognize that patients with severe COVID-19 have a shorter period of preoperative morbidity and may recover with intensive post-operative rehabilitation, hence we encourage but do not require pre-transplant rehabilitation. Finally, some patients with severe COVID-19 have multi-organ failure. Whether multi-organ transplant for these patients is safe or feasible will require additional consideration.

Whereas we believe that our study supports the consideration of lung transplantation for patients who have developed irreversible lung disease due to COVID-19, more studies are needed to determine the long-term outcomes of lung transplantation in these patients. Additionally, although our machine learning-based transcriptomics analysis supports the use of KRT17+KRT5- basaloid cells or profibrotic alveolar macrophages in bronchoscopic biopsies as markers of irreversible lung disease in patients with severe COVID-19, further clinical studies are necessary to validate these findings.

\section{MATERIALS AND METHODS}

\section{Study Design}

The current study included the first three consecutive patients undergoing lung transplantation for severe COVID-19.
In addition, lung biopsies were collected from patients who died from severe COVID-19 or other lung diseases. Patient demographic and clinical data were collected prospectively in our lung transplant database. For the purposes of the study a retrospective analysis was performed using the database. This study was approved by the Institutional Review Board of Northwestern University (STU00212120, STU00213177, STU00212511 and STU00212579). For inclusion in this study, patients or their designated medical power of attorney provided informed consent.

\section{Clinical characteristics of patients}

The three patients with COVID-19 who underwent lung transplantation are described in the main text and Table 1.

Post-mortem biopsy patient 1 (PMB1). A 54 year-old man with medically controlled hyperlipidemia presented with five days of dyspnea, cough, and diarrhea. A nasopharyngeal swab was positive for SARS-CoV-2 infection. He was intubated for acute hypoxemic respiratory failure. Ventilator management was guided by ARDSNET guidelines and the patient underwent three rounds of proning. However, he developed worsening hypoxemia and hypercapnia, necessitating initiation of veno-venous ECMO. Throughout the ECMO support, he underwent verticalization therapy to improve lung recruitment. His medical course spanning 29 days was complicated with acute renal failure, spontaneous hemothorax, pulmonary hemorrhage, and ventilator-associated pneumonia. He first tested negative for SARS-CoV-2 in bronchoalveolar fluid samples on day 27 after symptom onset. He received hydroxychloroquine, Remdesivir, and Sarilumab. However, he progressed to multiorgan dysfunction and care was withdrawn, after which he expired within $40 \mathrm{~min}$. Within one hour of death, warm autopsy of the left lung was performed. The tissue was processed for single cell RNA sequencing and SHIELD tissue clearing.

Post-mortem biopsy patient 2 (PMB2). A 57-year old woman with no known medical conditions presented with dyspnea and was initially treated with a one week course of steroids and hydroxychloroquine. She was intubated for acute hypoxemic respiratory failure. She was managed with prone ventilation based on ARDSNET guidelines. Following intubation, she received Remdesivir but she continued to worsen requiring veno-venous ECMO. She received broadspectrum antibiotics and systemic anticoagulation throughout her clinical course. She first tested negative for SARSCoV-2 in bronchoalveolar fluid samples 31 days after admission. The medical course was complicated by multiorgan multipressor shock. Forty eight days after admission, medical care was redirected to comfort care and the patient expired within $10 \mathrm{~min}$. Within one hour of expiration, the left lung was biopsied and processed for single cell RNA sequencing and SHIELD tissue clearing.

Palliative COVID-19 patient. An 81-year old woman with 
end stage renal disease and cirrhosis was admitted for a fever of 101.3F. She had a positive nasopharyngeal swab for SARSCoV-2. The patient developed increased $\mathrm{O}_{2}$ requirements and was subsequently transferred to the COVID-19 ICU. In the ICU, the patient developed hypotension and after discussion with the clinical team, the patient's family elected to focus on comfort care. The patient died 8 days after admission. A lung biopsy was taken at autopsy for sm-FISH to detect SARS-CoV2 RNA.

\section{ICU management for lung transplant patients}

Lung transplant case 2 received most of his care at a referring hospital where the details of his management were not known. At Northwestern University, case 2 and the other two patients (cases 1 and 3) were managed according to a standardized care plan for patients with COVID-19 that is similar to care for patients with ARDS. Specifically, all patients received mechanical ventilation according to ARDSNET criteria (low tidal volume, high PEEP) (6). Patients received prone ventilation when the $\mathrm{PaO}_{2} / \mathrm{FiO}_{2}$ ratio was $<150$; this was repeated for 16 hours daily until criteria were no longer met (7). Patients underwent bronchoalveolar lavage when pneumonia was suspected, and antibiotic therapy was guided by quantitative cultures or the results of multiplex PCR analysis of bronchoalveolar fluid samples (BioFire FilmArray Respiratory Viral Panel 2).

\section{Lung biopsy tissue fixation and thick slicing}

Human lung biopsies collected during native lung explant or during post-mortem biopsy were sliced to $5 \mathrm{~mm}$ thickness and placed in $4 \%$ paraformaldehyde solution for 72 hours at room temperature. Samples were then exchanged to $70 \%$ ethanol and stored in $4^{\circ} \mathrm{C}$ until use. Biopsies were also sent to the clinical pathology laboratories where they were fixed, paraffin embedded and stained according to standard clinical protocols.

Biopsy samples were sliced to $100 \mu \mathrm{m}$ thickness using a VT1200S Leica vibratome at $3.0 \mathrm{~mm}$ amplitude and $0.7 \mathrm{~mm} / \mathrm{s}$ speed. For healthy lung biopsies, $100 \mu \mathrm{m}$ thick slices were made at $3.0 \mathrm{~mm}$ amplitude and $0.35-0.4 \mathrm{~mm} / \mathrm{s}$ speed with ice in the holding chambers. Slices were stored in a tissue culture plate in $1 \mathrm{X}$ phosphate buffered saline (PBS) with $0.2 \%$ sodium azide, the tops and sides were sealed in parafilm. Plates were stored in $4^{\circ} \mathrm{C}$ until use.

\section{RNAscope on paraffin-embedded lung slices}

RNAscope Multiplex V2 manual assay from ACDbio was performed on paraffin embedded $5 \mu \mathrm{m}$ slices of lung tissue using mild digest times according to manufacturer instructions as we have described (14). Probes used were RNAscope Probe-V-nCoV2019-S-C3 (catalog number 848561) with Akoya Bio Opal Dye 520 using the 488 laser line and RNAscope Probe-nCoV2019-orflab-sense-C2 (catalog number 859151) with Opal Dye 690 using 640 laser line. After RNAscope assay was complete, slides were washed in TBST (1X TBS pH 7.6 with $500 \mu \mathrm{L}$ Tween-20) for $2 \mathrm{~min}$ with agitation twice. Slides were incubated in the dark at room temperature for $30 \mathrm{~min}$ with $10 \%$ normal goat serum in $1 \mathrm{X}$ TBS with $1 \%$ bovine serum albumin (BSA). Blocking solution was removed from slides via flicking. Slides were then incubated in primary antibody solution using CD206 Antibody (C-10) AF546 from Santa Cruz Biotechnology (RRID:AB_10989352) at 1:100 dilutions in TBS $1 \%$ BSA for $1 \mathrm{~h}$ at room temperature in the dark. Slides were rinsed using TBST for 5 min with agitation twice. Slides were rinsed in TBST buffer for 5 min twice. Slides were then mounted and dried overnight. Images were taken in the Center for Advanced Microscopy at Northwestern University Feinberg School of Medicine using the Nikon W1-Spinning Disk Confocal microscope. Nucleus was added to the images using machine-based learning network trained on one patient using DAPI and brightfield images in Nikon Elements. Final images were rendered using Fiji.

\section{SHIELD fixation and imaging of lung tissue}

The $100 \mu \mathrm{m}$ lung slices were secondarily fixed using a derivation of the SHIELD fixation protocol (34). Slices were placed in clean 12-well tissue culture plate with $1 \mathrm{~mL}$ of SHIELD-Off solution (1:1:2 of ddH2O: SHIELD Buffer: SHIELD Epoxy). Plate was incubated at $4^{\circ} \mathrm{C}$ for 4.8 hours with agitation. Slices were transferred to a clean plate containing $1 \mathrm{~mL}$ of SHIELD-On solution (1:1 SHIELD-On Buffer: SHIELD Epoxy) and incubated for 2.4 hours at room temperature with agitation. Slices were cleared using passive methods, slices were placed in clean 12 -well plate with LifeCanvas Passive Clearance Buffer at $37^{\circ} \mathrm{C}$ with agitation until slices were opaque; for healthy lung tissue incubate for 30-60 min, for diseased lung slices incubate for approximately 4 hours. Slices were washed overnight in PBS with 1\% Triton-X-100 (PBST). Slices were stained in 1:10,000 dilution of Hoescht 33342 in PBST overnight. Slices were washed three times for 20 min in PBST after staining. Slices were placed in LifeCanvas Easy Index solution in a clean tissue culture plate for index matching.

The cleared tissue slices were imaged in the Center for Advanced Microscopy at Northwestern University Feinberg School of Medicine using the Nikon W1-Spinning Disk Confocal microscope in a glass bottom dish at 20X magnification. The 3D images were rendered using Fiji.

\section{Single cell RNA sequencing of lung tissue}

Single cell RNA sequencing was performed using modifications to our published protocols (14). Distal lung biopsies were obtained from the explanted lung and donor lung from Case 1, and the two post-mortem biopsies. Two biopsies that included the main left bronchus and distal parenchyma from the upper lobe were obtained from another donor lung that was not placed for transplant (Donor 1). A single biopsy from a distal lung parenchyma (Donor 2) was obtained from wedge 
resection of the donor lung for size reduction during lung transplantation. Lung and airway tissues were infused with a solution of Collagenase $\mathrm{D}(2 \mathrm{mg} / \mathrm{ml})$ and DNase I $(0.1 \mathrm{mg} / \mathrm{ml})$ in RPMI, cut into $\sim 2 \mathrm{~mm}$ pieces and incubated in $10 \mathrm{ml}$ of digestion buffer with mild agitation for $30 \mathrm{~min}$. The resulting single cell suspension was filtered through a $70 \mu \mathrm{m}$ nylon mesh filter and digestion was stopped by addition of $10 \mathrm{ml}$ of PBS supplemented with 0.5\% BSA and $2 \mathrm{nM}$ EDTA (staining buffer). Cells were pelleted by centrifugation at $300 \mathrm{rcf}$ for 10 min, supernatant was removed and erythrocytes were lysed using $5 \mathrm{ml}$ of $1 \mathrm{x}$ Pharm Lyse solution (BD Pharmingen) for 3 min. The single cell suspension was resuspended in Fc-Block (Human TruStain FcX, Biolegend) and incubated with CD31 microbeads (Miltenyi Biosciences; 130-091-935) and the positive fraction, containing endothelial cells and macrophages was collected. The negative fraction was then resuspended in staining buffer, the volume was adjusted so the concentration of cells was always less than $5 \times 10^{7}$ cells $/ \mathrm{ml}$ and the fluorophore-conjugated antibody cocktail was added in 1:1 ratio (EpCAM, Clone 9C4, PECy7, BioLegend Cat\# 324222, RRID:AB_2561506, 1:40; CD206, Clone 19.2, PE, ThermoFisher Cat\# 12-2069-42, RRID:AB_10804655, 1:40; CD31, Clone WM59, APC, BioLegend Cat\# 303116, RRID: AB_1877151, 1:40; CD45 Clone HI30, APCCy7, BioLegend Cat\# 304014, RRID: AB_314402, 1:40; HLA-DR, Clone LN3, eFluor450, ThermoFisher Cat\# 48-9956-42, RRID:AB_10718248, 1:40). After incubation at $4^{\circ} \mathrm{C}$ for $30 \mathrm{~min}$ cells were washed with $5 \mathrm{ml}$ of MACS buffer, pelleted by centrifugation and resuspended in $500 \mathrm{ul}$ of MACS buffer $+2 \mathrm{ul}$ of SYTOX Green viability dye (ThermoFisher). Cells were sorted on FACS Aria III SORP instrument using a 100 um nozzle and 20 psi pressure. Macrophages were sorted as live/CD45 ${ }^{+}$HLA-DR ${ }^{+} \mathrm{CD} 206^{+}$cells, epithelial cells were sorted as live/CD45-CD31-EpCAM ${ }^{+}$, stromal cells were sorted as live/CD45-CD31-EpCAM ${ }^{-}$cells. Sample processing was performed in BSL-2 conditions using BSL-3 practices. Cells were sorted into $2 \%$ BSA in DPBS, pelleted by centrifugation at 300 rcf for $5 \mathrm{~min}$ at $4^{\circ} \mathrm{C}$, resuspended in $0.1 \%$ BSA in DPBS to $\sim 1000$ cells/ul concentration. Concentration was confirmed using K2 Cellometer (Nexcelom) with AO/PI reagent and $\sim 5,000-10,000$ cells were loaded on a 10x Genomics Chip B with Chromium Single Cell 3' gel beads and reagents (3' GEX V3, 10x Genomics). Libraries were prepared according to the manufacturer's protocol (10x Genomics, CG000183_RevB). After quality check single cell RNA-seq libraries were pooled and sequenced on a HiSeq 4000 or NovaSeq 6000 instrument. Data was processed using Scanpy ${ }^{5}$ v1.5.1, doublets were detected with scrublet ${ }^{6}$ v0.2.1 and removed, samples were integrated with $\mathrm{BBKNN}^{7}$ v1.3.12, cells were clustered with leiden algorithm, and clusters were manually annotated.

To compare cell types in lung tissue biopsies from patients with COVID-19-induced lung fibrosis to those in lung tissue from patients with IPF, we obtained a dataset reported in Habermann et al. (1) using the accession number GSE135893. We then trained the scArches algorithm on the Habermann et al. dataset and used it to integrate data from COVID-19 patient lung tissue. Briefly, scArches uses auto-encoder neural networks to find a low-dimensional representation of the original dataset (reference) and performs transfer learning to project another dataset (query) into the same latent space. Despite being low-dimensional, this latent space preserves transcriptomic variability of different cell types as well as heterogeneity within a given cell type. We used cell type annotations from Habermann et al. on our dataset to separate cells by lineage, and performed clustering independently for cell lineages using latent space coordinates as input. The diagnosis metadata field was merged for both datasets and used for cluster composition analysis and for computing differentially expressed genes.

\section{Statistics}

Patient demographics, postoperative complications, and outcomes were analyzed in the COVID-19 patient group who underwent lung transplantation. Continuous variables were reported as medians (interquartile means). Categorical variables were reported as number (percentage). Statistical analyses were performed using Stata/MP14 (StataCorp).

\section{SUPPLEMENTARY MATERIALS}

stm.sciencemag.org/cgi/content/full/scitranslmed.abe4282/DC1

Figure S1. Common histological features of warm lung autopsies.

Figure S2. Single cell RNA sequencing identifies similarities between end-stage pulmonary fibrosis and organizing pneumonia resulting from COVID-19.

Table S1. Description of the specimens used in this study.

Table S2. Marker genes for epithelial cell, macrophage and mesenchymal cell clusters.

Table S3. Differentially expressed genes in COVID-19 and IPF lung samples for each epithelial cell cluster.

Table S4. Differentially expressed genes in COVID-19 and IPF lung samples for each macrophage cluster.

Table S5. Differentially expressed genes in COVID-19 and IPF lung samples for each mesenchymal cell cluster.

Movie S1. Three-dimensional matrix imaging of COVID-19 and non-COVID-19 lung tissue.

\section{REFERENCES AND NOTES}

1. J. Geleris, Y. Sun, J. Platt, J. Zucker, M. Baldwin, G. Hripcsak, A. Labella, D. K. Manson, C. Kubin, R. G. Barr, M. E. Sobieszczyk, N. W. Schluger, Observational Study of Hydroxychloroquine in Hospitalized Patients with Covid-19. N. Engl. J. Med. 382, 2411-2418 (2020). doi:10.1056/NEJMoa2012410 Medline

2. S. Richardson, J. S. Hirsch, M. Narasimhan, J. M. Crawford, T. McGinn, K. W. Davidson, D. P. Barnaby, L. B. Becker, J. D. Chelico, S. L. Cohen, J. Cookingham, K. Coppa, M. A. Diefenbach, A. J. Dominello, J. Duer-Hefele, L. Falzon, J. Gitlin, N. Hajizadeh, T. G. Harvin, D. A. Hirschwerk, E. J. Kim, Z. M. Kozel, L. M. Marrast, J. N. Mogavero, G. A. Osorio, M. Qiu, T. P. Zanos; the Northwell COVID-19 Research Consortium, Presenting Characteristics, Comorbidities, and Outcomes Among 5700 Patients Hospitalized With COVID-19 in the New York City Area. JAMA 323 2052-2059 (2020). doi:10.1001/jama.2020.6775 Medline

3. P. Horby, W. S. Lim, J. R. Emberson, M. Mafham, J. L. Bell, L. Linsell, N. Staplin, C. Brightling, A. Ustianowski, E. Elmahi, B. Prudon, C. Green, T. Felton, D. Chadwick, 
K. Rege, C. Fegan, L. C. Chappell, S. N. Faust, T. Jaki, K. Jeffery, A. Montgomery, K. Rowan, E. Juszczak, J. K. Baillie, R. Haynes, M. J. Landray; RECOVERY Collaborative Group, Dexamethasone in Hospitalized Patients with Covid-19 Preliminary Report. N. Engl. J. Med. (2020). Medline

4. J. H. Beigel, K. M. Tomashek, L. E. Dodd, A. K. Mehta, B. S. Zingman, A. C. Kalil, E. Hohmann, H. Y. Chu, A. Luetkemeyer, S. Kline, D. Lopez de Castilla, R. W. Finberg, K. Dierberg, V. Tapson, L. Hsieh, T. F. Patterson, R. Paredes, D. A. Sweeney, W. R. Short, G. Touloumi, D. C. Lye, N. Ohmagari, M. Oh, G. M. Ruiz-Palacios, T. Benfield, G. Fätkenheuer, M. G. Kortepeter, R. L. Atmar, C. B. Creech, J. Lundgren, A. G. Babiker, S. Pett, J. D. Neaton, T. H. Burgess, T. Bonnett, M. Green, M. Makowski, A. Osinusi, S. Nayak, H. C. Lane, Remdesivir for the Treatment of Covid-19 Preliminary Report. Reply. N. Engl. J. Med. 383, 994 (2020). doi:10.1056/NEJMoa2007764 Medline

5. S. C. van der Mark, R. A. S. Hoek, M. E. Hellemons, Developments in lung transplantation over the past decade. Eur. Respir. Rev. 29, 190132 (2020). doi:10.1183/16000617.0132-2019 Medline

6. R. G. Brower, P. N. Lanken, N. MacIntyre, M. A. Matthay, A. Morris, M. Ancukiewicz, D. Schoenfeld, B. T. Thompson; National Heart, Lung, and Blood Institute ARDS Clinical Trials Network, Higher versus lower positive end-expiratory pressures in patients with the acute respiratory distress syndrome. N. Engl. J. Med. 351, 327336 (2004). doi:10.1056/NEJMoa032193 Medline

7. C. Guérin, J. Reignier, J.-C. Richard, P. Beuret, A. Gacouin, T. Boulain, E. Mercier, M. Badet, A. Mercat, O. Baudin, M. Clavel, D. Chatellier, S. Jaber, S. Rosselli, J. Mancebo, M. Sirodot, G. Hilbert, C. Bengler, J. Richecoeur, M. Gainnier, F. Bayle, G. Bourdin, V. Leray, R. Girard, L. Baboi, L. Ayzac; PROSEVA Study Group, Prone positioning in severe acute respiratory distress syndrome. N. Engl. J. Med. 368 , 2159-2168 (2013). doi:10.1056/NEJMoa1214103 Medline

8. C. Kurihara, J. M. Walter, B. D. Singer, H. Cajigas, S. Shayan, A. Al-Qamari, M. M. DeCamp, R. Wunderink, G. R. S. Budinger, A. Bharat, Extracorporeal Membrane Oxygenation Can Successfully Support Patients With Severe Acute Respiratory Distress Syndrome in Lieu of Mechanical Ventilation. Crit. Care Med. 46, e1070e1073 (2018). doi:10.1097/CCM.0000000000003354 Medline

9. A. Bharat, M. M. DeCamp, Veno-arterial extracorporeal membrane oxygenation without therapeutic anticoagulation for intra-operative cardiopulmonary support during lung transplantation. J. Thorac. Dis. 9, E629-E631 (2017). doi:10.21037/itd.2017.06.11 Medline

10. J. Tomasko, S. M. Prasad, D. O. Dell, M. M. DeCamp, A. Bharat, Therapeutic anticoagulation-free extracorporeal membrane oxygenation as a bridge to lung transplantation. J. Heart Lung Transplant. 35, 947-948 (2016). doi:10.1016/i.healun.2016.04.005 Medline

11. K. L. Wood, B. Ayers, I. Gosev, N. Kumar, A. L. Melvin, B. Barrus, S. Prasad, Venoarterial-Extracorporeal Membrane Oxygenation Without Routine Systemic Anticoagulation Decreases Adverse Events. Ann. Thorac. Surg. 109, 1458-1466 (2020). doi:10.1016/i.athoracsur.2019.08.040 Medline

12. M. Ackermann, S. E. Verleden, M. Kuehnel, A. Haverich, T. Welte, F. Laenger, A. Vanstapel, C. Werlein, H. Stark, A. Tzankov, W. W. Li, V. W. Li, S. J. Mentzer, D. Jonigk, Pulmonary Vascular Endothelialitis, Thrombosis, and Angiogenesis in Covid-19. N. Engl. J. Med. 383, 120-128 (2020). doi:10.1056/NEJMoa2015432 Medline

13. I. Sola, F. Almazán, S. Zúñiga, L. Enjuanes, Continuous and Discontinuous RNA Synthesis in Coronaviruses. Annu. Rev. Virol. 2, 265-288 (2015). doi:10.1146/annurev-virology-100114-055218 Medline

14. P. A. Reyfman, J. M. Walter, N. Joshi, K. R. Anekalla, A. C. McQuattie-Pimentel, S. Chiu, R. Fernandez, M. Akbarpour, C.-I. Chen, Z. Ren, R. Verma, H. AbdalaValencia, K. Nam, M. Chi, S. Han, F. J. Gonzalez-Gonzalez, S. Soberanes, S. Watanabe, K. J. N. Williams, A. S. Flozak, T. T. Nicholson, V. K. Morgan, D. R. Winter, M. Hinchcliff, C. L. Hrusch, R. D. Guzy, C. A. Bonham, A. I. Sperling, R. Bag, R. B. Hamanaka, G. M. Mutlu, A. V. Yeldandi, S. A. Marshall, A. Shilatifard, L. A. N. Amaral, H. Perlman, J. I. Sznajder, A. C. Argento, C. T. Gillespie, J. Dematte, M. Jain, B. D. Singer, K. M. Ridge, A. P. Lam, A. Bharat, S. M. Bhorade, C. J. Gottardi, G. R. S. Budinger, A. V. Misharin, Single-Cell Transcriptomic Analysis of Human Lung Provides Insights into the Pathobiology of Pulmonary Fibrosis. Am. J. Respir. Crit. Care Med. 199, 1517-1536 (2019). doi:10.1164/rccm.201712-24100C Medline

15. E. Valenzi, M. Bulik, T. Tabib, C. Morse, J. Sembrat, H. Trejo Bittar, M. Rojas, R.
Lafyatis, Single-cell analysis reveals fibroblast heterogeneity and myofibroblasts in systemic sclerosis-associated interstitial lung disease. Ann. Rheum. Dis. 78, 1379-1387 (2019). doi:10.1136/annrheumdis-2018-214865 Medline

16. A. C. Habermann, A. J. Gutierrez, L. T. Bui, S. L. Yahn, N. I. Winters, C. L. Calvi, L. Peter, M.-I. Chung, C. J. Taylor, C. Jetter, L. Raju, J. Roberson, G. Ding, L. Wood, J. M. S. Sucre, B. W. Richmond, A. P. Serezani, W. J. McDonnell, S. B. Mallal, M. J. Bacchetta, J. E. Loyd, C. M. Shaver, L. B. Ware, R. Bremner, R. Walia, T. S. Blackwell, N. E. Banovich, J. A. Kropski, Single-cell RNA sequencing reveals profibrotic roles of distinct epithelial and mesenchymal lineages in pulmonary fibrosis. Sci. Adv. 6, eaba1972 (2020). doi:10.1126/sciadv.aba1972 Medline

17. T. S. Adams, J. C. Schupp, S. Poli, E. A. Ayaub, N. Neumark, F. Ahangari, S. G. Chu, B. A. Raby, G. Deluliis, M. Januszyk, Q. Duan, H. A. Arnett, A. Siddiqui, G. R. Washko, R. Homer, X. Yan, I. O. Rosas, N. Kaminski, Single-cell RNA-seq reveals ectopic and aberrant lung-resident cell populations in idiopathic pulmonary fibrosis. Sci. Adv. 6, eaba1983 (2020). doi:10.1126/sciadv aba1983 Medline

18. M. Strunz, L. M. Simon, M. Ansari, J. J. Kathiriya, I. Angelidis, C. H. Mayr, G. Tsidiridis, M. Lange, L. F. Mattner, M. Yee, P. Ogar, A. Sengupta, I. Kukhtevich, R. Schneider, Z. Zhao, C. Voss, T. Stoeger, J. H. L. Neumann, A. Hilgendorff, J. Behr, M. O'Reilly, M. Lehmann, G. Burgstaller, M. Königshoff, H. A. Chapman, F. J. Theis, H. B. Schiller, Alveolar regeneration through a Krt8+ transitional stem cell state that persists in human lung fibrosis. Nat. Commun. 11, 3559 (2020). doi:10.1038/s41467-020-17358-3 Medline

19. Y. Kobayashi, A. Tata, A. Konkimalla, H. Katsura, R. F. Lee, J. Ou, N. E. Banovich, J. A. Kropski, P. R. Tata, Persistence of a regeneration-associated, transitional alveolar epithelial cell state in pulmonary fibrosis. Nat. Cell Biol. 22, 934-946 (2020). doi:10.1038/s41556-020-0542-8 Medline

20. P. Jiang, R. Gil de Rubio, S. M. Hrycaj, S. J. Gurczynski, K. A. Riemondy, B. B. Moore, M. B. Omary, K. M. Ridge, R. L. Zemans, Ineffectual Type 2-to-Type 1 Alveolar Epithelial Cell Differentiation in Idiopathic Pulmonary Fibrosis: Persistence of the KRT8hi Transitional State. Am. J. Respir. Crit. Care Med. 201, 1443-1447 (2020). doi:10.1164/rccm.201909-1726LE Medline

21. H. Wu, Y. Yu, H. Huang, Y. Hu, S. Fu, Z. Wang, M. Shi, X. Zhao, J. Yuan, J. Li, X. Yang, E. Bin, D. Wei, H. Zhang, J. Zhang, C. Yang, T. Cai, H. Dai, J. Chen, N. Tang, Progressive Pulmonary Fibrosis Is Caused by Elevated Mechanical Tension on Alveolar Stem Cells. Cell 180, 107-121.e17 (2020). doi:10.1016/j.cell.2019.11.027 Medline

22. A. V. Misharin, L. Morales-Nebreda, P. A. Reyfman, C. M. Cuda, J. M. Walter, A. C. McQuattie-Pimentel, C.-I. Chen, K. R. Anekalla, N. Joshi, K. J. N. Williams, H. Abdala-Valencia, T. J. Yacoub, M. Chi, S. Chiu, F. J. Gonzalez-Gonzalez, K. Gates, A. P. Lam, T. T. Nicholson, P. J. Homan, S. Soberanes, S. Dominguez, V. K. Morgan, R. Saber, A. Shaffer, M. Hinchcliff, S. A. Marshall, A. Bharat, S. Berdnikovs, S. M. Bhorade, E. T. Bartom, R. I. Morimoto, W. E. Balch, J. I. Sznajder, N. S. Chandel, G. M. Mutlu, M. Jain, C. J. Gottardi, B. D. Singer, K. M. Ridge, N. Bagheri, A. Shilatifard, G. R. S. Budinger, H. Perlman, Monocyte-derived alveolar macrophages drive lung fibrosis and persist in the lung over the life span. J. Exp. Med. 214, 2387-2404 (2017). doi:10.1084/jem.20162152 Medline

23. E. Valenzi, M. Bulik, T. Tabib, C. Morse, J. Sembrat, H. Trejo Bittar, M. Rojas, R. Lafyatis, Single-cell analysis reveals fibroblast heterogeneity and myofibroblasts in systemic sclerosis-associated interstitial lung disease. Ann. Rheum. Dis. 78, 1379-1387 (2019). doi:10.1136/annrheumdis-2018-214865 Medline

24. N. Joshi, S. Watanabe, R. Verma, R. P. Jablonski, C.-I. Chen, P. Cheresh, N. S Markov, P. A. Reyfman, A. C. McQuattie-Pimentel, L. Sichizya, Z. Lu, R. PiseauxAillon, D. Kirchenbuechler, A. S. Flozak, C. J. Gottardi, C. M. Cuda, H. Perlman, M. Jain, D. W. Kamp, G. R. S. Budinger, A. V. Misharin, A spatially restricted fibrotic niche in pulmonary fibrosis is sustained by M-CSF/M-CSFR signalling in monocyte-derived alveolar macrophages. Eur. Respir. J. 55, 1900646 (2020). doi:10.1183/13993003.00646-2019 Medline

25. X. Zhou, R. A. Franklin, M. Adler, J. B. Jacox, W. Bailis, J. A. Shyer, R. A. Flavell, A. Mayo, U. Alon, R. Medzhitov, Circuit Design Features of a Stable Two-Cell System. Cell 172, 744-757.e17 (2018). doi:10.1016/i.cell.2018.01.015 Medline

26. R. Wölfel, V. M. Corman, W. Guggemos, M. Seilmaier, S. Zange, M. A. Müller, D. Niemeyer, T. C. Jones, P. Vollmar, C. Rothe, M. Hoelscher, T. Bleicker, S. Brünink, J. Schneider, R. Ehmann, K. Zwirglmaier, C. Drosten, C. Wendtner, Virological assessment of hospitalized patients with COVID-2019. Nature 581, 465-469 (2020). doi:10.1038/s41586-020-2196-x Medline 
27. M. M. Arons, K. M. Hatfield, S. C. Reddy, A. Kimball, A. James, J. R. Jacobs, J. Taylor, K. Spicer, A. C. Bardossy, L. P. Oakley, S. Tanwar, J. W. Dyal, J. Harney, Z. Chisty, J. M. Bell, M. Methner, P. Paul, C. M. Carlson, H. P. McLaughlin, N. Thornburg, S. Tong, A. Tamin, Y. Tao, A. Uehara, J. Harcourt, S. Clark, C. Brostrom-Smith, L. C. Page, M. Kay, J. Lewis, P. Montgomery, N. D. Stone, T. A. Clark, M. A. Honein, J. S. Duchin, J. A. Jernigan; Public Health-Seattle and King County and CDC COVID-19 Investigation Team, Presymptomatic SARS-CoV-2 Infections and Transmission in a Skilled Nursing Facility. N. Engl. J. Med. 382 2081-2090 (2020). doi:10.1056/NEJMoa2008457 Medline

28. J. Bullard, K. Dust, D. Funk, J. E. Strong, D. Alexander, L. Garnett, C. Boodman, A Bello, A. Hedley, Z. Schiffman, K. Doan, N. Bastien, Y. Li, P. G. Van Caeseele, G. Poliquin, Predicting infectious SARS-CoV-2 from diagnostic samples. Clin. Infect. Dis. ciaa638 (2020). doi:10.1093/cid/ciaa638 Medline

29. A. V. Misharin, L. Morales-Nebreda, P. A. Reyfman, C. M. Cuda, J. M. Walter, A. C. McQuattie-Pimentel, C.-I. Chen, K. R. Anekalla, N. Joshi, K. J. N. Williams, H. Abdala-Valencia, T. J. Yacoub, M. Chi, S. Chiu, F. J. Gonzalez-Gonzalez, K. Gates, A. P. Lam, T. T. Nicholson, P. J. Homan, S. Soberanes, S. Dominguez, V. K. Morgan, R. Saber, A. Shaffer, M. Hinchcliff, S. A. Marshall, A. Bharat, S. Berdnikovs, S. M. Bhorade, E. T. Bartom, R. I. Morimoto, W. E. Balch, J. I. Sznajder, N. S. Chandel, G. M. Mutlu, M. Jain, C. J. Gottardi, B. D. Singer, K. M. Ridge, N. Bagheri, A. Shilatifard, G. R. S. Budinger, H. Perlman, Monocyte-derived alveolar macrophages drive lung fibrosis and persist in the lung over the life span. J. Exp. Med. 214, 2387-2404 (2017). doi:10.1084/jem.20162152 Medline

30. N. H. Juul, C. A. Stockman, T. J. Desai, Niche Cells and Signals that Regulate Lung Alveolar Stem Cells In Vivo. Cold Spring Harb. Perspect. Biol. (2020).

31. A. N. Nabhan, D. G. Brownfield, P. B. Harbury, M. A. Krasnow, T. J. Desai, Singlecell Wnt signaling niches maintain stemness of alveolar type 2 cells. Science 359 , 1118-1123 (2018). doi:10.1126/science.aam6603 Medline

32. J. A. Zepp, W. J. Zacharias, D. B. Frank, C. A. Cavanaugh, S. Zhou, M. P. Morley, E. E. Morrisey, Distinct Mesenchymal Lineages and Niches Promote Epithelial SelfRenewal and Myofibrogenesis in the Lung. Cell 170, 1134-1148.e10 (2017). doi:10.1016/i.cell.2017.07.034 Medline

33. J. Chen, H. Wu, Y. Yu, N. Tang, Pulmonary alveolar regeneration in adult COVID-19 patients. Cell Res. 30, 708-710 (2020). doi:10.1038/s41422-020-0369-7 Medline

34. Y. G. Park, C. H. Sohn, R. Chen, M. McCue, D. H. Yun, G. T. Drummond, T. Ku, N. B. Evans, H. C. Oak, W. Trieu, H. Choi, X. Jin, V. Lilascharoen, J. Wang, M. C. Truttmann, H. W. Qi, H. L. Ploegh, T. R. Golub, S. C. Chen, M. P. Frosch, H. J. Kulik, B. K. Lim, K. Chung, Protection of tissue physicochemical properties using polyfunctional crosslinkers. Nat. Biotechnol. (2018). Medline

Acknowledgments: We thank pathology residents Taylor Zak and Megan Kinn for processing the human lung samples. We also thank Elena Susan for administrative assistance. Funding: This work was supported by National Institutes of Health (NIH) grants HL145478, HL147290, and HL147575 (to AB), U19AI135964, P01AG049665, R01HL153312, NUCATS COVID-19 Rapid Response Grant, CZI Seed Networks for the Human Cell Atlas (to AVM), and P01AG049665, R01HL147575, U19Al135964, and Veterans Affairs grant I01CX001777 (to GRSB). The Northwestern University Flow Cytometry Core Facility and Northwestern Center for Advanced Microscopy are supported by $\mathrm{NCl}$ Cancer Center Support Grant P30 CA060553 awarded to the Robert H. Lurie Comprehensive Cancer Center. This study was supported in part through the computational resources and staff contributions provided by the Genomics Compute Cluster, which is jointly supported by the Feinberg School of Medicine, the Center for Genetic Medicine, and Feinberg's Department of Biochemistry and Molecular Genetics, the Office of the Provost, the Office for Research, and Northwestern Information Technology. The Genomics Compute Cluster is part of Quest, Northwestern University's high-performance computing facility with the goal of advancing research in genomics. Author contributions: AB, SM, CK, RGC, RT, AVM, GRSB performed data collection and analysis, and specimen collection; MQ performed experiments involving sm-FISH and lung imaging with SHIELD technology; NSM performed bioinformatics analysis; AM performed clinical data collection and analysis; AS and YP supervised bioinformatics analysis; HAV performed single cell RNA sequencing; AVY and JWL provided histological analysis of the explanted lung tissue and autopsy specimens. All authors contributed to writing of the manuscript. Competing interests: The authors declare no competing interests. Data and Materials Availability: All data associated with this study are in the main text or supplementary materials. Single cell RNA sequencing count matrices and metadata are available at GEO accession number GSE158127. Detailed analysis code for single cell RNA sequencing is available at https://zenodo.org/record/4291961. This work is licensed under a Creative Commons Attribution 4.0 International (CC BY 4.0) license, which permits unrestricted use, distribution, and reproduction in any medium, provided the original work is properly cited. To view a copy of this license, visit https://creativecommons.org/licenses/by/4.0/. This license does not apply to figures/photos/artwork or other content included in the article that is credited to a third party; obtain authorization from the rights holder before using this material.

Submitted 20 August 2020

Accepted 22 November 2020

Published First Release 30 November 2020

10.1126/scitranslmed.abe4282 

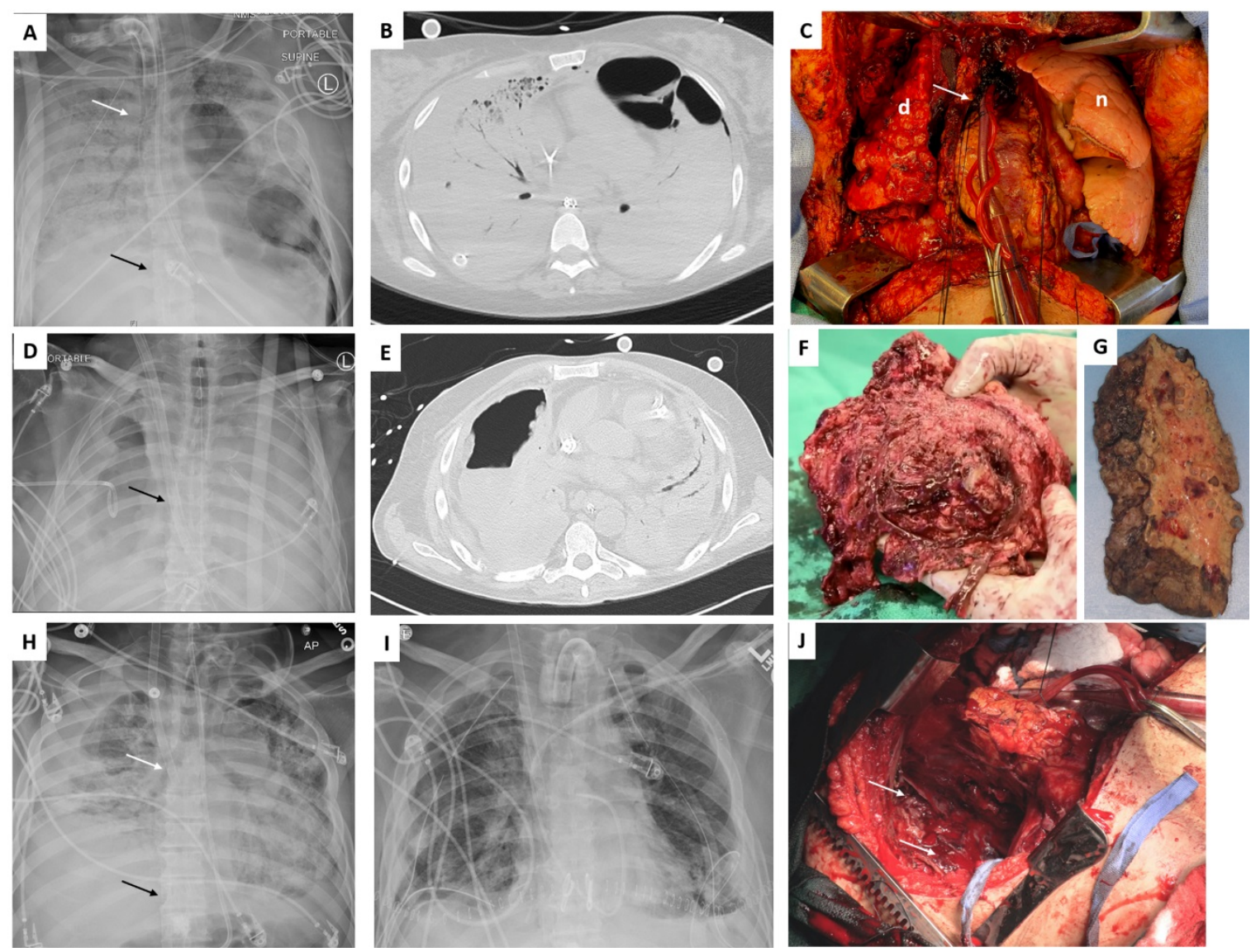

Fig. 1. Radiographic and intraoperative findings in lung transplant recipients with severe COVID-19. (A-C) Shown are the radiographic and intraoperative findings for case 1 with severe COVID-19 who underwent lung transplantation. (A) Shown is the pre-transplant chest radiograph (day 38 after onset of ARDS) for case 1, revealing opacification of the right lung and a left lower lobe necrotic cavity attributed to pneumonia caused by Serratia marcascens. A tube thoracostomy was required to treat right spontaneous hemothorax and peumothoraces. Additionally, the image shows ECMO cannulas (inflow cannula carrying oxygenated blood to the patient is indicated by the white arrow and outflow cannula carrying deoxygenated blood from the patient to the ECMO machine is indicated by the black arrow). (B) Severe ARDS and lower lung lobe necrosis in case 1 was confirmed by cross-sectional computed tomography imaging. (C) Shown is an intraoperative image revealing contrasting features between the diseased native right lung (d) and the newly transplanted left lung (n). The photograph was taken immediately following the transplant of the left lung and before proceeding onto right lung transplantation. The pericardial sac (white arrow) containing the heart was opened to gain access to the aorta and place the outflow cannula of the veno-arterial ECMO. (D-F) Shown are the radiographic and intraoperative findings for case 2 with severe COVID-19, who underwent lung transplantation. (D) Shown is the pretransplant chest radiograph (at day 98 after onset of ARDS) for case 2 revealing bilateral lung opacifications and a necrotic cavity in the right lung attributed to pneumonia caused by Pseudomonas aeruginosa. A chest tube to treat bronchopleural fistula is visible. The dual lumen ECMO cannula is indicated by the black arrow. (E) Computed tomography imaging indicates severe ARDS and development of a necrotic cavity in the right lung. (F) Shown is the freshly explanted right lung of case 2 with extensive pleural inflammation and loss of identifiable anatomical planes. (G) Shown is the formalin-fixed explanted right lung of case 1 demonstrating the development of lung cavities. (H-J) Shown are the radiographic and intraoperative findings for case 3 with severe COVID-19, who underwent lung transplantation. (H) Shown is the pre-transplant chest radiograph (day 86 after onset of severe ARDS) for case 3, revealing extensive consolidation (lack of air) with right fibrothorax. Additionally, the image shows ECMO cannulas (inflow cannula carrying oxygenated blood to the patient is indicated by the white arrow and the outflow cannula carrying deoxygenated blood from the patient to the ECMO machine is indicated by the black arrow). (I) Shown is a post-transplant day 1 chest radiograph for case 3 demonstrating the expected appearance of new lung allografts after bilateral lung transplantation. (J) Shown is an intraoperative photograph after implantation of the left lung and explantation of the right lung revealing the right hemithorax. Diffuse pleuritis with severe thickening of parietal pleura and neo-angiogenesis (white arrows) were noted as in the other two cases. 

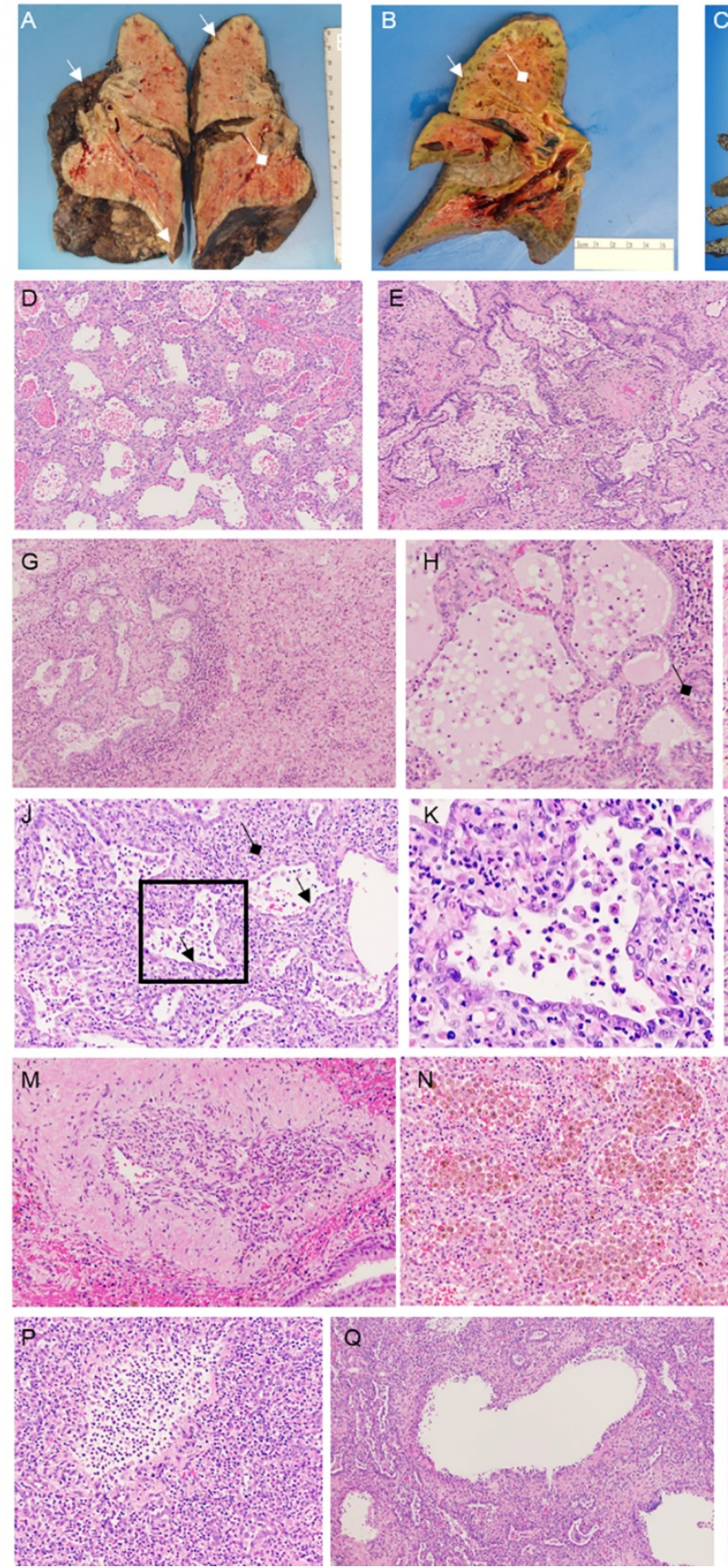
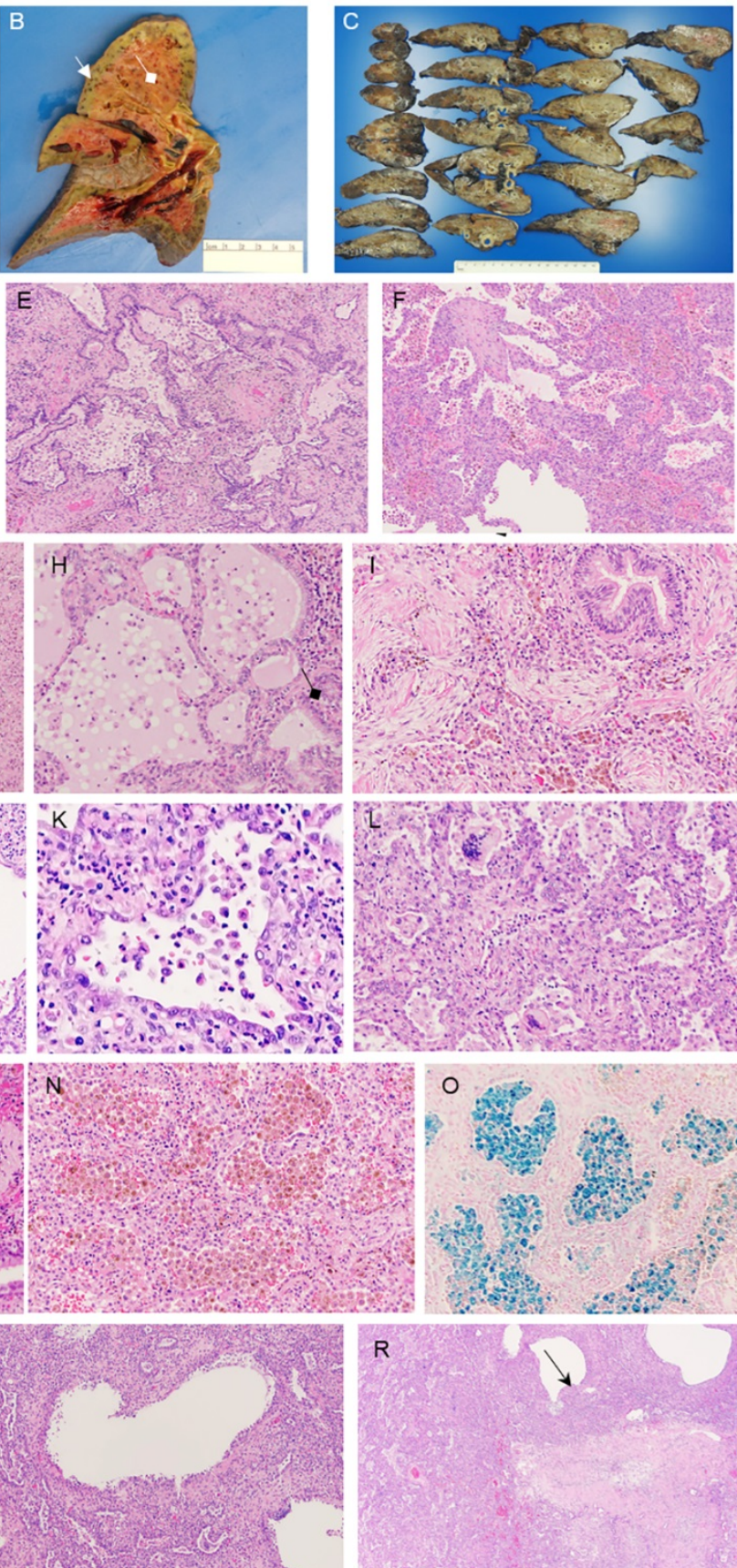

Fig. 2. Common histological features of lung explants. Shown are common histological features of lung explants from three patients with severe COVID-19 who underwent lung transplantation. (A-C) Shown are gross pathology images of explanted lungs from case 1 (image $A$ ), case 2 (image B), and case 3 (image $C$ ). Cystic structures are evident on the lung surface and in the lung parenchyma (white arrows) along with diffuse fibrosis. Purulent secretions in the airways suggestive of bronchopneumonia are indicated by white diamond arrows. (D-R) Remaining images show sections of explanted lung from cases 1,2 and 3 stained with hematoxylin and eosin, except for image $\mathrm{O}$, which was stained with Prussian Blue to detect iron deposition. (D) Image shows lung alveoli in explanted lung from case 1 demonstrating hemorrhage, interstitial fibrosis and prominent reactive pneumocytes (100X). (E) Bronchiolitis and bronchiolar fibrosis with microscopic honeycombing were observed for explanted lung from case 2 (200X). (F) Organizing areas of alveolar hemorrhage are visible on this image of explanted lung from case 3 (100X). (G) Microscopic honeycombing adjacent to an area of more dense fibrosis with interstitial expansion and inflammatory infiltrates is visible on this image of explanted lung from case 2 (100X). (H) Bronchiolitis and fibrosis (black diamond arrow) are visible on this image of explanted lung from case 2 (200X). (I) An area of organizing

pneumonia showing whorls of fibroblasts in the airways and interstitial expansion is observed on this image of explanted lung from case 2 (200X). (J) Interstitial fibrosis and bronchiolar fibrosis (black arrows) are visible in this image of explanted lung from case 2 (100X). (K) Enlarged inset from panel J reveals a bronchiole surrounded by interstitial fibrosis and cuboidal epithelia. $(L)$ Area of interstitial fibrosis and microscopic honeycombing with multinucleated giant cells in the airspaces is visible on this image of explanted lung from case 1 (200X). (M) A mediumsize blood vessel with an organizing thrombus and recannulation can be observed in this image of explanted lung from case 2 (100X). (N) Interstitial inflammation and expansion with alveoli filled with pigmented macrophages is visible in this image of explanted lung from case $1(100 X)$. (0) Staining for iron revealed alveolar macrophages laden with hemosiderin (blue) in this image of explanted lung from case 1 (100X). (P) This image of explanted lung from case 1 shows formation of cystic airspaces with neutrophilic inflammatory infiltrates (200X). (Q) This image of explanted lung from case 1 reveals cystic airspaces lined by histiocytes and hyperplastic epithelia (100X), and (R) this image reveals a mature cyst (black arrow) near an area of airway fibrosis (40X). 

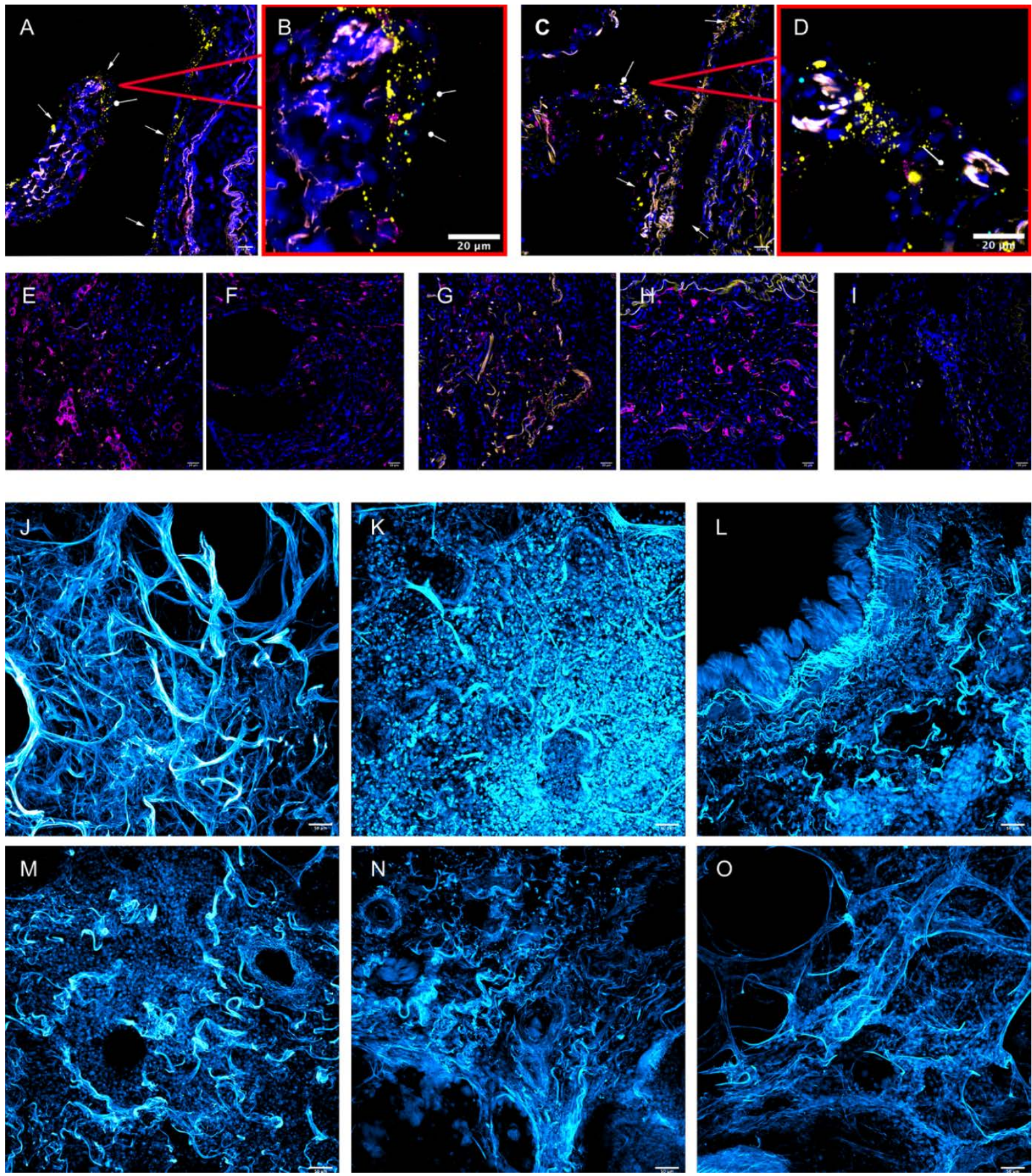

Fig. 3. sm-FISH and matrix imaging in cleared lung sections from patients with severe COVID-19. (A-D) Shown are RNAScope and immunohistochemistry of lung autopsy tissue from a patient who declined interventions for COVID-19-induced respiratory failure (Palliative COVID-19). Nuclear staining (blue), positive strand SARS-CoV-2 RNA (yellow), negative strand SARS-CoV-2 RNA (cyan), CD206 (magenta). (A, B) Positive strand SARS-CoV-2 RNA (yellow) was detected in cells with morphological features suggestive of epithelial cells (white arrows); negative strand SARS-CoV-2 RNA was also detected (cyan; circular arrow). (E, F) RNAScope images of the explanted lung from case 1 who underwent lung transplantation. There is yellow autofluorescence but no staining for SARSCov-2 positive or negative strand RNA in either left $(E)$ or right $(F)$ explanted lung. $(G, H)$ RNAScope images of the explanted lung of case 2 who underwent lung transplantation, showing no evidence of SARS-CoV-2 RNA. (I) RNAScope image of a post-mortem lung biopsy from a patient who died of COVID-19 (PMB1), showing no evidence of SARS-CoV-2 RNA. (J-O) Shown is cleared lung tissue allowing visualization of the collagen structure and matrix of lung tissue (cyan); 20x magnification. (J) Shown is a normal lung from a patient who died of pulmonary embolism. (K) Shown is an explanted lung from case 1 who underwent lung transplantation. (L, M) Shown are post-mortem lung biopsies from two patients who died of COVID-19 (PMB1, PMB2). (N, O) Shown are lung explants from two patients with idiopathic pulmonary fibrosis (IPF1, IPF2), who underwent lung transplantation. 
A

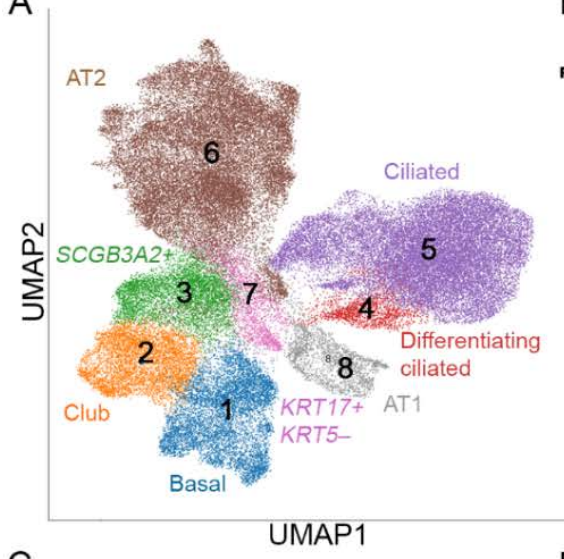

C

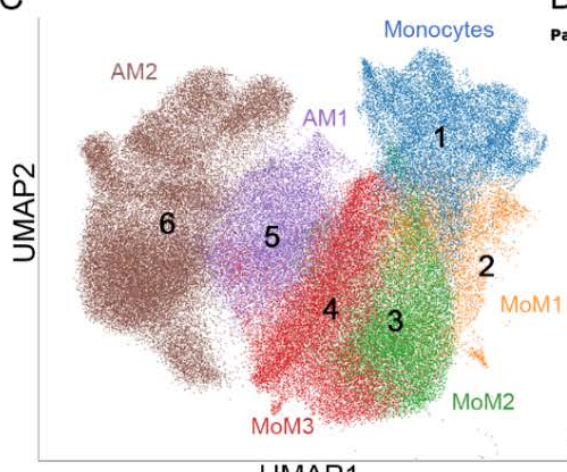

E

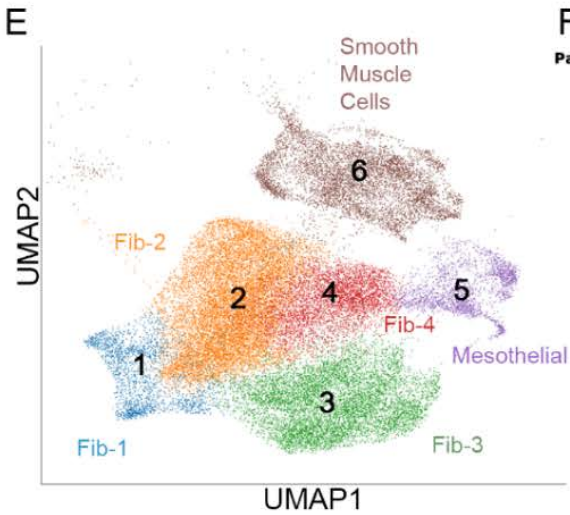

G

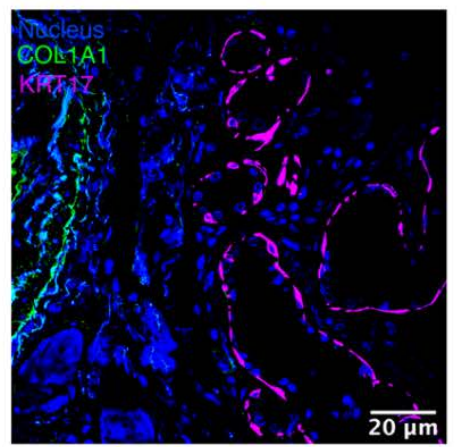

$\mathrm{H}$
B

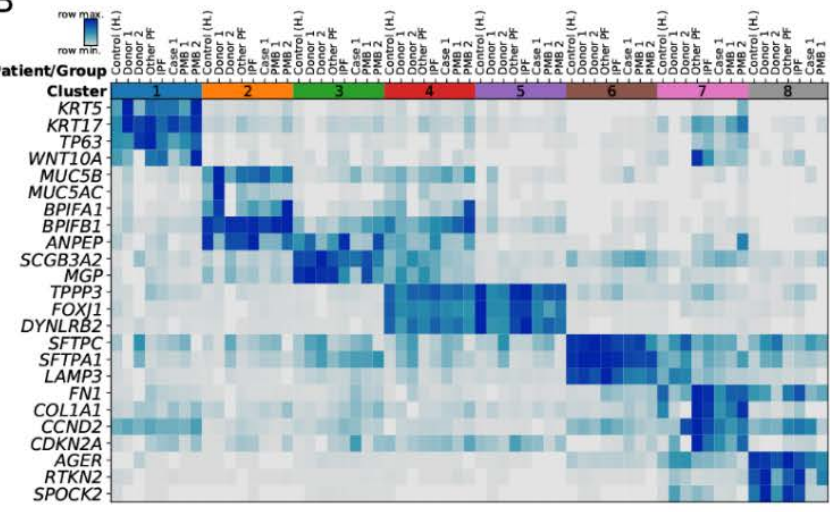

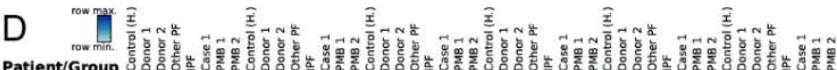

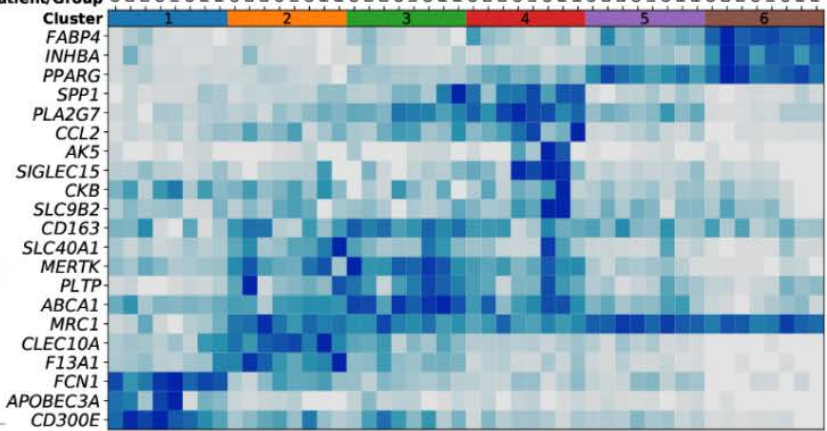

F rom how Cluster
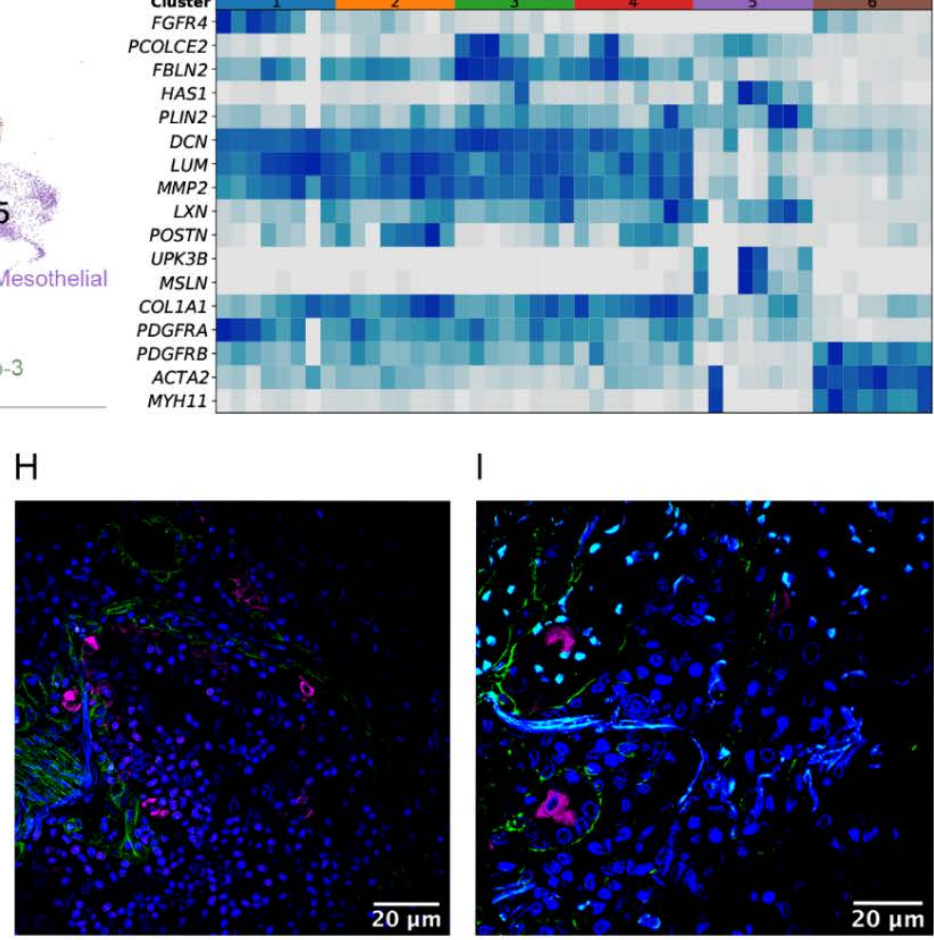

I

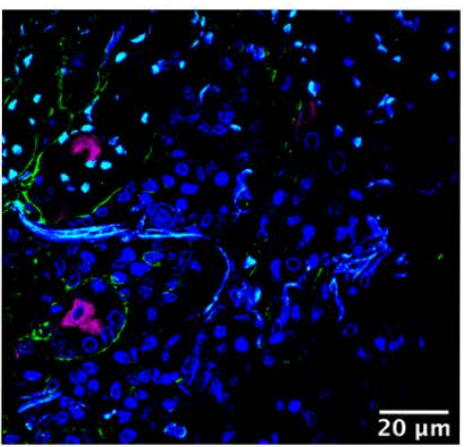

Fig. 4. Single cell RNA sequencing of lung tissue from patients with severe COVID-19. (A, C, E) Presented are Uniform Manifold Approximation and Projection (UMAP) plots showing individual populations of epithelial cells (A), macrophages (C), and mesenchymal cells (E). (B,D,F) Shown are heatmaps illustrating expression of select marker genes in epithelial cells (B), macrophages (D), and mesenchymal cells $(F)$. Gene expression for the pulmonary fibrosis dataset of Habermann et al. (16) is shown as an average per condition; gene expression for the end-stage COVID-19 dataset is shown per individual patient. Labels on heatmaps (B, D, F) correspond to the following samples: Control $(\mathrm{H})$, healthy controls; IPF, idiopathic pulmonary fibrosis samples; other PF, samples from patients with other forms of pulmonary fibrosis, all from the Habermann et al. dataset. Donor 1, Donor 2, control donor lungs; Case 1, lung transplant case 1; PMB1, PMB2, postmortem lung biopsies from two COVID-19 patients, all from the endstage COVID-19 dataset. (G) Immunofluorescence microscopy revealed KRT17 staining (purple) of flat epithelial cells resembling alveolar type 1 cells in nonfibrotic lung tissue from a patient who died of COVID-19 (Palliative COVID-19). (H, I) Immunofluorescence microscopy revealed KRT17 staining (purple) of distal explanted lung tissue from a COVID-19 patient undergoing lung transplantation $(\mathrm{H})$ and lung tissue from a patient (PMB1) who died from latestage severe COVID-19 (I).

Normal lung architecture is lacking and solitary KRT17-positive cells (purple) can be observed close to COL1A1-positive cells (green). Scale bar, 20 um. 
Table 1. Clinical characteristics of lung transplant recipients.

\begin{tabular}{lc} 
Variable & COVID-19 \\
& patients (3) \\
\hline Age, years & $44.3 \pm 13.9$ \\
Female & $1(33.3 \%)$ \\
BMI, kg/m2 & $25.2 \pm 4.5$ \\
Operating time (hours) & $9.5 \pm 1.0$ \\
Intraoperative blood transfusion & \\
pRBC & $10.6 \pm 4.1$ \\
FFP & $5.3 \pm 2.4$ \\
Plt & $2.6 \pm 1.2$ \\
Intraoperative VA ECMO use & $3(100 \%)$ \\
Intraoperative VA ECMO time & $2.8 \pm 0.3$ \\
(hours) & $5.1 \pm 0.1$ \\
Ischemic time (hours) & $13.3 \pm 7.0$ \\
ICU stay (days) & $12.6 \pm 8.3$ \\
Post transplant ventilator (days) & $20.3 \pm 4.4$ \\
Pleural drainage (days) &
\end{tabular}

Continuous data are shown as means \pm standard deviation (SD). BMI, Body Mass Index; VV ECMO, Veno-Venous ExtraCorporeal Membrane Oxygenation; ICU, Intensive Care Unit 